\title{
Recovery from eating disorders: psychometric properties of a patient-related measure
}

\author{
This article was published in the following Dove Press journal: \\ Patient Related Outcome Measures \\ 22 November 2012 \\ Number of times this article has been viewed
}

\section{Gunn Pettersen' \\ Kari-Brith Thune-Larsen ${ }^{2}$ \\ Jan H Rosenvinge ${ }^{3}$ \\ 'Department of Health and Care Sciences, Faculty of Health Sciences, University of Troms $\varnothing$, Troms $\varnothing$, Norway; ${ }^{2} \mathrm{O}$ slo University Hospital, Oslo, Norway; ${ }^{3}$ Department of Psychology, Faculty of Health Sciences, University of Tromsø, Tromsø, Norway}

Correspondence: Gunn Pettersen University of Tromsø, Department of Health and Care Sciences, N-9037 Tromsø, Norway

Tel +47 77660699

Fax +47 77660612

Email gunn.pettersen@uit.no

\begin{abstract}
Although there are numerous lists of items covering clinically valid aspects of recovery from eating disorders, these lists are on the nominal level: the potential for multidimensional development has not been explored. Such exploration is the purpose of the present study. The subjects included in the study were 152 female clinicians, 1052 females randomly selected from the general population, and 184 eating-disorder patients. All subjects rated 17 recovery items on a 10-point scale in terms of their relevance and importance. They also completed measures of knowledge about eating disorders and their own eating problems, in addition to providing information about their age and personal acquaintance with eating disorders. Fourteen recoveryitem scores were sample unspecific, and hence all samples tended to judge the majority of items in a similar manner. The 17 items successfully formed three separate factors covering specific eating-disorder symptoms, as well as social and psychological issues. The clinician and general population sample analyzed together provided a more condensed scale comprising two factors (specific eating-disorder symptoms and psychosocial factors), with each factor having three items. This factor structure was successfully replicated using the patient-validation sample. The findings indicate an empirical basis for a valid recovery measure that may be suitable in future outcome research.
\end{abstract}

Keywords: eating disorders, recovery, outcome, outcome measures

\section{Introduction}

Eating disorders are characterized by at least four clusters of clinical manifestations and consequences from which recovery is necessary. First, physical elements of recovery comprise the absence of physical consequences from weight loss in anorexia nervosa ${ }^{1}$ and the excessive bingeing and purging ${ }^{2-4}$ in bulimia nervosa that may lower the risk of a poor prognosis. ${ }^{5}$ Recovery also comprises behavioral as well as cognitive and emotional elements, that is, attitudes about eating, weight, and shape, as well as a variety of weight-control behaviors. ${ }^{6-11}$ They are core clinical features of a cognitive understanding of eating disorders, and are probably responsible for the best-evidenced treatment of these disorders. ${ }^{12}$ Patient studies ${ }^{13-16}$ indicate that cognitive and behavioral recovery may pave the way for interpersonal and psychosocial elements of recovery, which comprise social and occupational functioning. Moreover, a failure to improve in the psychosocial elements of recovery is associated with a poor outcome, especially in bulimia nervosa and the diagnostically unspecific eating disorders. ${ }^{17,18}$

Despite a general agreement in the literature about these clusters' relevance to recovery, literature reviews $\mathrm{s}^{5,17-19}$ show that these elements are not consistently included in recovery assessments. This is partly responsible for a huge variation in outcome 
findings ${ }^{7,8,20}$ that makes it difficult to accumulate comparable knowledge about this group of mental disorders of high mortality and the potentials for recovery. ${ }^{21,22}$ A clinical consequence of such variation may be erroneous identification of a patient's recovery, which may misguide treatment or aftercare.

Problems with existing and widely used measures may be another partial explanation of why multidimensionality is invariably represented in outcome studies. Some measures of symptom load and emotional and cognitive recovery elements ${ }^{23-28}$ developed for clinical settings may be too timeconsuming to perform within the context of a follow-up study, where brief and quickly administred instruments are preferred. Other measures that include psychosocial aspects ${ }^{29}$ are flawed by variable interrater reliability. ${ }^{30,31}$ Another explanation refers to differences of opinion over the relative importance and relevance of the recovery elements. These differences vary along a restrictive-inclusive dimension manifested by three approaches that might be used to classify the study of recovery from eating disorders. ${ }^{16}$ A negation approach is restricted to defining recovery as the absence of diagnostic criteria for eating disorders. A clinical approach is more inclusive by the adding of emotional, cognitive, and psychosocial elements of recovery. These approaches are generated from overall judgments made by clinicians and researchers. The experiential approach, on the other hand, comprises patients' subjective opinions, and is highly inclusive. Here, recovery is a matter of the subjective experience of wellbeing, which does not hinge on a complete absence of diagnostically or clinically relevant features, for example, body image or dieting. Moreover, the absence of eating-disorder symptoms may even represent new challenges that may temper the subjective experience of being recovered. ${ }^{15}$

In principle, all approaches stand the risk of biased attributions. Clinician's judgments may be biased by attributing special relevance to recovery elements consistent with their view about the nature of eating disorders and what it takes to recover, or they may be biased by selective normative opinions about normality. Patients, on the other hand, may attribute recovery to factors of remote relevance, or their judgments may be influenced by their current eating-disorder symptoms.

Comparative multisample and multiapproach studies represent a step forward toward testing biases and developing measures of recovery that are psychometrically and clinically valid, yet brief enough to be used in outcome research. Comparing patient and therapist opinions about the relevance of many elements of recovery derived from a clinical approach ${ }^{32-36}$ lends some support to patients' selecting inclusive elements (eg, wellbeing) and clinicians' selecting the more restricted features, (eg, dicting and weight preoccupation) yet such findings are flawed by low statistical power, the failure to control for gender and age, or the therapist's clinical experience in multivariate analyses. Overall, however, comparative studies ${ }^{32-34,36}$ show more congruence than incongruence across samples with respect to aspects considered necessary and sufficient for a recovery.

Congruence with respect to recovery criteria adds to the external validity and lowers the risk for biases. Such congruence may also help to prevent inconsistent expectations between therapists and patients about therapy output. Conversely, incongruent expectations are related to an increased risk for treatment dropout, ${ }^{37}$ which in turn increases the risk for a poorer final outcome. ${ }^{38}$ However, the congruence issue needs to be further pursued by expanding multidimensionality to capture larger variation in samples and approaches to recovery.

General population data for validation purposes have been collected for some of the clinical assessment measures ${ }^{23-26}$ that can be used to tailor cognitive, behavioral, and emotional recovery. However, this customary validation strategy has not been used in previous comparative recovery studies. The inclusion of a general population sample may provide a test of common sense and face validity, and may be a way to test the specificity of probable biases from patients or therapists about the nature of and recovery from eating disorders. Hence, the present comparison study includes a general population sample, a clinician sample and an eating-disorder patient sample. Relying on the existing comparisons, a reasonable hypothesis is that no major sample differences will appear. A further critical congruence test is to use multivariate methods to identify the number and nature of recovery items surviving as sample independent (ie, congruent) despite the introduction of alternative variables. Age, clinical experience, acquaintance with eating disorders, and having eatingdisorder symptoms may all influence how recovery items are judged in terms of relevance and importance. This issue has not been explored in previous research.

Previous comparative studies are limited by the fact that lists of recovery items remain on a nominal level of measurement without exploring potentials for multidimensional scale development. For obvious reasons, a psychometrically valid recovery scale may yield a mean or a sum score with a statistical variation that could be used in multivariate outcome research. Furthermore, clinically derived lists of items believed to cover aspects of recovery tend to be rather lengthy. A large number of items may limit their use 
in ordinary clinical work and in outcome research, and they may contain redundant items or items covering particular clinical interests. Factor analyses may then be appropriate as an item reduction strategy; they also to identify meaningful item clusters and possible subscales. Only one previous study ${ }^{34}$ has used such a strategy, however, with little success in reducing the number of items.

The present study used a multifaceted set of recovery items derived from the negation, clinical, as well as from an experiential approach to explore the following research questions:

1. Do eating-disorder patients, clinicians specialized in treating eating disorders, and people from the general population rank recovery items for eating disorders in a similar manner?

2. To what extent do age, current eating-disorder symptoms, knowledge about eating disorders, and personal acquaintance or experience with eating disorders influence the judgment of the relevance and importance of clinically and experientially derived recovery items?

3. Can recovery items be developed into a psychometric instrument with a clinically meaningful factor structure?

4. Can a factor structure be replicated in a sample of patients with eating disorders?

\section{Methods}

\section{Subjects}

All female clinicians $(\mathrm{N}=152$, age range $20-60$ years $)$ participating in a national advanced education program to raise clinical competence in eating disorders took part in the current study. Moreover, The Royal Bureau of Official Statistics, Norway, was hired in order to perform the proper method of randomly selecting a comparison group from the general population stratified to comprise women in the age range of 20-45 years. Of the original sample of 1152 women, 1052 respondents $(91.3 \%)$ returned the questionnaire forms. A patient-validation sample consisted of 184 consecutive eating-disorder patients currently in therapy at a tertiary treatment center for eating disorders. The sample covered all diagnostic categories, that is, anorexia nervosa ( $38 \%, \mathrm{~N}=70)$, bulimia nervosa $(31 \%, \mathrm{~N}=57)$, binge eating disorder $(7 \%, \mathrm{~N}=13)$, and eating disorders not otherwise specified $(34 \%, N=44)$. Sample information appears in Table 1.

\section{Assessment}

Inspired by previous studies on attitudes and knowledge about eating disorders, ${ }^{39,40}$ and by experiential studies of patient perspectives, ${ }^{41} 17$ items were developed to cover the

Table I Recovery items in order of form appearance

\begin{tabular}{|c|c|c|c|c|c|c|c|c|c|}
\hline \multirow[t]{2}{*}{ Recovery items/sample information/covariates } & \multicolumn{3}{|c|}{$\begin{array}{l}\text { General population } \\
(\mathbf{N}=1052)\end{array}$} & \multicolumn{3}{|c|}{$\begin{array}{l}\text { Clinicians } \\
(N=152)\end{array}$} & \multicolumn{3}{|c|}{$\begin{array}{l}\text { Eating disorder patients } \\
(\mathbf{N}=184)\end{array}$} \\
\hline & $\mathbf{M}$ & SD & Rank & $\mathbf{M}$ & SD & Rank & $\mathbf{M}$ & SD & Rank \\
\hline Normal weight & 6.74 & 2.47 & 16 & 6.02 & 2.32 & 17 & 6.50 & 2.90 & 16 \\
\hline No dieting and other damaging symptoms & 7.94 & 2.05 & 10 & 6.27 & 3.13 & 15 & 8.60 & 2.39 & 5 \\
\hline Regular menstruation & 6.31 & 2.68 & 17 & 6.28 & 3.00 & 13 & 6.83 & 3.13 & 13 \\
\hline Improved attitude to body and appearance & 9.60 & 1.01 & I & 6.64 & 3.59 & 3 & 8.88 & 1.77 & 3 \\
\hline Improved quality of life & 8.66 & 1.65 & 6 & 6.65 & 3.61 & 2 & 9.29 & $\mathbf{I . 5 5}$ & $\mathbf{I}$ \\
\hline Understand why one got an eating disorder & 9.22 & 1.29 & 2 & 6.43 & 2.86 & 8 & 6.96 & 2.52 & 12 \\
\hline Recognise thoughts and feelings that elicit symptoms & 9.15 & 1.29 & 4 & 6.58 & 3.62 & 4 & 8.53 & 2.10 & 7 \\
\hline Being confident about feelings & 9.16 & 1.26 & 3 & 6.79 & 3.42 & $\mathrm{I}$ & 7.84 & 2.30 & 10 \\
\hline No symptoms to cope with challenges or crises & 8.25 & 1.85 & 8 & 6.41 & 1.96 & 9 & 8.10 & 2.26 & 9 \\
\hline Less perfectionism & 7.86 & 1.34 & 12 & 6.14 & 2.98 & 16 & 6.79 & 2.50 & 14 \\
\hline Improved general condition & 8.22 & $\mathrm{I} .82$ & 9 & 6.40 & 3.14 & 10 & 8.78 & 2.03 & 4 \\
\hline Better family relations & 7.68 & 2.04 & 13 & 6.39 & 2.82 & I I & 7.84 & 2.53 & 10 \\
\hline Better relations toward mother & 6.83 & 2.35 & 15 & 6.26 & 2.49 & 14 & 6.70 & 2.97 & 15 \\
\hline Better social network & 8.28 & 1.84 & 7 & 6.44 & 2.95 & 7 & 8.34 & 2.08 & 8 \\
\hline Taking part in social activities & 8.75 & 1.54 & 5 & 6.50 & 3.09 & 6 & 8.59 & 1.83 & 6 \\
\hline Functioning well at school or job & 7.45 & 2.18 & 14 & 6.54 & 3.14 & 5 & 9.29 & I.5I & 2 \\
\hline Recognizing pressure towards thinness & 7.92 & 2.23 & II & 6.32 & 2.65 & 12 & 6.36 & 2.81 & 17 \\
\hline Age in years & 29.94 & 5.12 & & 44.77 & 8.13 & & 28.96 & 8.30 & \\
\hline Knowledge about eating disorders (range I-I0) & 6.71 & 0.65 & & 6.94 & 0.63 & & - & - & \\
\hline Eating disturbances (EDS-5) (range 5-35) & 14.75 & 7.52 & & 13.60 & 4.40 & & 24.30 & 8.17 & \\
\hline Acquaintance/experience with eating disorders (range I-I0) & 6.84 & 5.12 & & 3.93 & 2.10 & & & & \\
\hline BMI & - & - & & - & - & & 21.81 & 6.54 & \\
\hline Duration of illness (months) & - & - & & - & - & & 12.77 & II.78 & \\
\hline
\end{tabular}

Note: Item differences of 5 or less in mean score-based ranking steps are printed in bold. 
multidimensional perspective on eating disorders defined by the four clusters of clinical manifestations and consequences from which recovery is necessary. Hence, the items covered physical elements ${ }^{1}$ (eg, the restoration of regular menstruation and normal weight, and the improvement in general physical condition); behavioral elements ${ }^{6-11}$ (eg, less dieting and other eating-disorder symptoms); cognitive and emotional aspects (eg, more functional affect regulation, affective confidence and coping strategies, and a more positive attitude toward one's body and physical appearance); psychosocial elements (eg, improved interpersonal and social relations); and sociocultural aspects (eg, recovery in terms of being more aware of a sociocultural pressure to be thin). Additional aspects covered perfectionism, occupational and social functioning, and understanding of previous and current factors causing or maintaining the eating disorder. Table 1 provides an account of all the 17 items. They were Likert scored, ranging from 1 to 10 (10 = maximal importance and relevance to recovery). The internal consistency was acceptable (Cronbach's alpha $=0.69)$. In accord with the transdiagnostic model of eating disorders ${ }^{12}$ and the considerable diagnostic fluctuations across time during the course of illness, ${ }^{4,42-44}$ recovery items were not created with the intention of ending up with items specific to diagnostic categories of eating disorders.

The subjects also completed a measure of eating problems, specifically, the Eating Disturbance Scale (EDS-5). ${ }^{45}$ It consists of five items, each with a Likert scoring of 1-7, where higher scores indicate more eating problems. A sum score thus yields a range from 5 to 35 ; scores less than 16 indicate a possible current eating disorder. ${ }^{45}$ The EDS-5 yields good internal consistency (Cronbach's $\alpha=0.84$ ). Finally, respondents were given one question about their knowledge about eating disorders and about the extent to which they had personal experiences or acquaintance with eating disorders from someone they knew personally. Both questions were rated on a 10-point scale, with 10 being the most affirmative response.

\section{Procedure}

All clinicians enrolled in the educational program received the questionnaire form personally, and they completed it at the program site. The form was mailed to subjects in the general population sample, who filled it out at home, while eating-disorder patients completed it at their routine clinic visits. All participants completed their questionnaire at one time point. The study was conducted according to the Helsinki declaration of medical ethics and was approved by the Regional Council of Medical and Healthcare Research.

\section{Data analyses}

Initially, bivariate correlations between items were performed for each sample. A multiple logistic regression analysis was used to test the probability of a sample-specific endorsement of recovery items, and to explore sample-specific and overall response sets. As the final step, a factor analysis was performed. Missing data points in the active general population sample were replaced by sample-specific means. All analyses were performed using SPSS software (version 16.0; IBM, Armonk, NY).

\section{Results}

\section{Similarity in ranking of recovery items across samples and the impact of alternative variables (research questions I and 2)}

Table 1 shows the samplewise ranking of the 17 recovery items based on mean scores (range 1-10). Due to a restricted range of mean scores, meaningful sample differences were defined as 5 or more. Overall, the rankings of 11 of the 17 items were not meaningfully different. Both when comparing the normal population and the clinician samples and when comparing the clinician and patient sample this proportion rose to 14 of 17 items. Some details from the rankings are noteworthy: a universal agreement across samples was that a recovered eating-disorder patient should display a positive attitude toward his or her body and appearance. Patients judged the absence of dieting and damaging symptoms as more important than did clinicians and people from the general population. Conversely, patients did not value the importance of being confident about their feelings. Moreover, only people from the general population valued the importance of understanding why one had an eating disorder.

Logistic regression analyses comprising the general population and the clinician samples represent, however, a stronger empirical test of sample-specific preferences. An initial analysis, where all the 17 recovery items were entered, successfully excluded 10 items for not being sample specific. Small odds ratios (ranging from 0.61 to 1.58 ) for the remaining items indicated that the sample specificity was modest (Table 2). A second analysis (Table 2) showed that when the additional measures were entered, 14 items were successfully excluded for not being sample specific in the final step model, again with a restricted odds ratio range (0.54-1.42) for the three remaining items. Moreover, not all additional measures were retained; the sample-specific recovery items were related to older age and self-reported 
Table 2 Recovery variables and additional variables entering the final step in a logistic regression analysis to predict sample ${ }^{a}$

\begin{tabular}{|c|c|c|c|c|}
\hline Improvement of & B & SE & Wald & $\mathbf{O R}^{95 \% \mathrm{Cl}}$ \\
\hline Weight & -0.14 & 0.06 & $6.13^{b}$ & $0.87^{0.78-0.97}$ \\
\hline Menstruation & 0.42 & 0.06 & $33.77^{d}$ & $1.52^{1.32-1.76}$ \\
\hline Body attitude & -0.48 & 0.07 & $35.93^{d}$ & $0.61^{0.53-0.72}$ \\
\hline $\begin{array}{l}\text { Understand why one got an } \\
\text { eating disorder }\end{array}$ & -0.48 & 0.08 & $42.46^{\mathrm{c}}$ & $0.62^{0.54-0.72}$ \\
\hline Social network & -0.26 & 0.07 & $9.42^{c}$ & $0.77^{0.65-0.91}$ \\
\hline Social activities & -0.28 & 0.09 & $11.67^{d}$ & $0.76^{0.64-0.89}$ \\
\hline School/job functioning & 0.46 & 0.10 & $23.19^{d}$ & $1.58^{1.31-1.90}$ \\
\hline \multicolumn{5}{|c|}{ Model $\chi^{2}(I)=2 I 7.4 I, P<0.000 I$, Cox \& Snell $R^{2}=0.27$} \\
\hline Menstruation & 0.35 & 0.10 & $12.08^{\mathrm{b}}$ & $1.42^{1.17-1.74}$ \\
\hline Body attitude & -0.33 & 0.11 & $8.75^{b}$ & $0.72^{0.57-0.89}$ \\
\hline $\begin{array}{l}\text { Understand why one got an } \\
\text { eating disorder }\end{array}$ & -0.61 & 0.13 & $22.93^{\mathrm{c}}$ & $0.54^{0.42-0.70}$ \\
\hline Age, yrs & 0.46 & 0.06 & $59.85^{c}$ & $1.59^{1.41-1.79}$ \\
\hline $\begin{array}{l}\text { Knowledge about eating } \\
\text { disorders }\end{array}$ & 1.76 & 0.37 & $22.43^{c}$ & $5.80^{2.80-12.0}$ \\
\hline $\begin{array}{l}\text { Acquaintance/experience } \\
\text { with eating disorders }\end{array}$ & -0.65 & 0.12 & $29.23^{c}$ & $0.53^{0.42-0.66}$ \\
\hline \multicolumn{5}{|c|}{ Model $\chi^{2}(I)=9.55, P<0.002$, Cox \& Snell $R^{2}=0.45$} \\
\hline
\end{tabular}

Notes: ${ }^{\mathrm{a}}\left(\mathrm{I}=\right.$ general population, $2=$ clinician sample); ${ }^{\mathrm{b} P}<0.00 \mathrm{I}$; ${ }^{\mathrm{c} P}<0.00 \mathrm{I}$; $\mathrm{d} P<0.0001$

knowledge about eating disorders among clinicians, and in the general population sample, to less personal knowledge or acquaintance with eating disorders. Hence, 14 of the 17 items could be successfully identified as unrelated to both samples and to the additional measures, and the sample-unspecific items covered all five elements of recovery, that is, the physical, behavioral, cognitive, and emotional, as well as the interpersonal and psychosocial, elements.
Development of a psychometrically sound recovery instrument (research questions 3 and 4)

Significant item intercorrelations (Tables 3 and 4), for the general and clinician samples indicate an empirical basis for factor structure explorations. Hence, in the clinician sample, $43 \%$ of the correlations were statistically significant and they ranged from $0.11-0.76$. The corresponding figures for the general population sample were $67 \%$ and a range $0.13-0.70$.

Factor analyses yielded a meaningful data organization in terms of three factors accounting for an accumulated variance of $52.9 \%$ in the clinician group and $51.0 \%$ in the general population group, respectively (Table 5). Table 5 also shows that the best factorial match between the samples was on factors 1 and 3 (ie, "social aspects" and "specific symptoms"). To further condense common factors, all items from factors 1 and 3 were entered into a new factor analysis comprising the combined general population and clinician samples. This produced a meaningful two-factor solution (Table 6), where the items were organized into a psychosocial or a symptom-specific factor. Both factors showed good internal consistency (Cronbach's $\alpha=0.82$ and 0.71 , respectively). As a clinical and psychometric validation strategy, a forced two-factor analysis using the pati-ent sample successfully replicated these findings (Table 6).

\section{Discussion}

The first main finding is that clinicians and people from the general population judge characteristics of recovery from ED rather similarly. This corresponds well to comparisons of clinically derived recovery characteristics between therapists

Table 3 Recovery Item correlations for the clinician sample

\begin{tabular}{|c|c|c|c|c|c|c|c|c|c|c|c|c|c|c|c|c|c|}
\hline & I & 2 & 3 & 4 & 5 & 6 & 7 & 8 & 9 & 10 & I I & 12 & 13 & 14 & 15 & 16 & 17 \\
\hline I & 1.0 & & & & & & & & & & & & & & & & \\
\hline 2 & 0.09 & 1.0 & & & & & & & & & & & & & & & \\
\hline 3 & 0.39 & 0.08 & 1.0 & & & & & & & & & & & & & & \\
\hline 4 & 0.19 & 0.02 & 0.23 & 1.0 & & & & & & & & & & & & & \\
\hline 5 & 0.32 & 0.16 & 0.36 & 0.41 & 1.0 & & & & & & & & & & & & \\
\hline 6 & 0.00 & 0.00 & 0.16 & 0.18 & 0.00 & 1.0 & & & & & & & & & & & \\
\hline 7 & 0.10 & 0.15 & 0.08 & 0.37 & 0.39 & 0.32 & 1.0 & & & & & & & & & & \\
\hline 8 & 0.23 & 0.01 & 0.1 I & 0.35 & 0.29 & 0.20 & 0.46 & 1.0 & & & & & & & & & \\
\hline 9 & -0.08 & 0.04 & -0.06 & 0.16 & 0.03 & 0.00 & 0.13 & 0.09 & 1.0 & & & & & & & & \\
\hline 10 & -0.22 & 0.15 & 0.07 & 0.21 & 0.11 & 0.27 & 0.23 & 0.25 & 0.27 & 1.0 & & & & & & & \\
\hline II & -0.12 & 0.13 & 0.05 & 0.10 & 0.15 & 0.01 & 0.12 & 0.00 & 0.14 & 0.10 & 1.0 & & & & & & \\
\hline 12 & 0.26 & 0.09 & 0.12 & 0.19 & 0.18 & 0.00 & 0.15 & 0.12 & 0.12 & 0.05 & 0.57 & 1.0 & & & & & \\
\hline 13 & 0.02 & 0.05 & 0.07 & 0.09 & 0.25 & 0.04 & 0.21 & 0.17 & 0.17 & 0.16 & 0.33 & 0.56 & 1.0 & & & & \\
\hline 14 & 0.03 & 0.09 & 0.13 & 0.15 & 0.15 & 0.05 & 0.19 & 0.12 & 0.04 & 0.08 & 0.54 & 0.62 & 0.52 & 1.0 & & & \\
\hline 15 & 0.12 & 0.07 & 0.14 & 0.11 & 0.24 & 0.00 & 0.13 & 0.11 & 0.05 & 0.02 & 0.55 & 0.60 & 0.41 & 0.67 & 1.0 & & \\
\hline 16 & 0.00 & 0.10 & 0.06 & 0.09 & 0.16 & -0.00 & 0.12 & 0.09 & 0.05 & 0.04 & 0.61 & 0.58 & 0.31 & 0.68 & 0.76 & 1.0 & \\
\hline 17 & 0.02 & 0.00 & 0.07 & 0.00 & 0.09 & 0.15 & 0.19 & 0.17 & 0.00 & 0.21 & 0.22 & 0.35 & 0.34 & 0.37 & 0.35 & 0.34 & 1.0 \\
\hline
\end{tabular}

Notes: $N=152$. Statistically significant correlations $(P<0.05)$ are printed in bold. 
Table 4 Recovery item correlations for the general population sample

\begin{tabular}{|c|c|c|c|c|c|c|c|c|c|c|c|c|c|c|c|c|c|}
\hline & $I$ & 2 & 3 & 4 & 5 & 6 & 7 & 8 & 9 & 10 & 11 & 12 & 13 & 14 & 15 & 16 & 17 \\
\hline I & 1.0 & & & & & & & & & & & & & & & & \\
\hline 2 & 0.41 & 1.0 & & & & & & & & & & & & & & & \\
\hline 3 & 0.44 & 0.37 & 1.0 & & & & & & & & & & & & & & \\
\hline 4 & 0.18 & 0.20 & 0.12 & 1.0 & & & & & & & & & & & & & \\
\hline 5 & 0.23 & 0.38 & 0.28 & 0.32 & 1.0 & & & & & & & & & & & & \\
\hline 6 & 0.15 & 0.26 & 0.18 & 0.38 & 0.37 & 1.0 & & & & & & & & & & & \\
\hline 7 & 0.13 & 0.25 & 0.15 & 0.34 & 0.40 & 0.60 & 1.0 & & & & & & & & & & \\
\hline 8 & 0.19 & 0.20 & 0.18 & 0.34 & 0.32 & 0.44 & 0.52 & 1.0 & & & & & & & & & \\
\hline 9 & 0.24 & 0.29 & 0.21 & 0.17 & 0.32 & 0.25 & 0.28 & 0.33 & 1.0 & & & & & & & & \\
\hline 10 & 0.21 & 0.20 & 0.19 & 0.16 & 0.21 & 0.13 & 0.16 & 0.24 & 0.43 & 1.0 & & & & & & & \\
\hline II & 0.42 & 0.36 & 0.33 & 0.23 & 0.28 & 0.23 & 0.20 & 0.26 & 0.18 & 0.06 & 1.0 & & & & & & \\
\hline 12 & 0.19 & 0.19 & 0.16 & 0.13 & 0.21 & 0.16 & 0.13 & 0.25 & 0.20 & 0.90 & 0.31 & 1.0 & & & & & \\
\hline 13 & 0.18 & 0.14 & 0.19 & 0.08 & 0.16 & 0.09 & 0.10 & 0.17 & 0.17 & 0.11 & 0.26 & 0.70 & 1.0 & & & & \\
\hline 14 & 0.19 & 0.22 & 0.21 & 0.22 & 0.16 & 0.18 & 0.11 & 0.21 & 0.14 & 0.12 & 0.35 & 0.55 & 0.49 & 1.0 & & & \\
\hline 15 & 0.12 & 0.11 & 0.12 & 0.13 & 0.12 & 0.13 & 0.10 & 0.13 & 0.10 & 0.09 & 0.11 & 0.00 & 0.05 & 0.06 & 1.0 & & \\
\hline 16 & 0.24 & 0.22 & 0.27 & 0.19 & 0.19 & 0.14 & 0.10 & 0.21 & 0.23 & 0.10 & 0.39 & 0.48 & 0.48 & 0.61 & 0.08 & 1.0 & \\
\hline 17 & 0.25 & 0.24 & 0.22 & 0.26 & 0.24 & 0.24 & 0.27 & 0.27 & 0.16 & 0.12 & 0.32 & 0.22 & 0.18 & 0.28 & 0.00 & 0.34 & 1.0 \\
\hline
\end{tabular}

Notes: $\mathrm{N}=1052$. Statistically significant correlations $(P<0.05)$ are printed in bold.

and eating-disorder patients. ${ }^{32,33}$ The ranking approach based on mean scores yielded small ranking differences, wherein overall, 11 of the 17 items were sample congruent, rising to 14 out of 17 when comparing the normal population and clinician samples only. Patients in the current study were still in treatment, and may thus have been in an early recovery stage. A previous finding ${ }^{33}$ that patients, especially those in earlier stages of recovery, tend to lend a selective importance to psychosocial criteria for recovery, is not supported by our findings. Our findings may then serve as an argument for validity, irrespective of recovery stages. This may be strengthened by similar sample congruent findings using logistic regression analyses that are more empirically stringent. When the additional measures were entered into

Table 5 A principal component analysis for the clinician sample $(\mathrm{N}=152)$ with a three-factor solution with varimax rotation

\begin{tabular}{|c|c|c|c|}
\hline Recovery items & & Factors and factor loadir & \\
\hline Improvement of & I. Social aspects & 2. Psychological aspects & 3. Specific symptoms \\
\hline Social network & $0.83[0.78]$ & & \\
\hline Relation towards mother & $0.8 \mathrm{I}[0.8 \mathrm{I}]$ & & \\
\hline Family relations & $0.78[0.83]$ & & \\
\hline Dieting pressure & $0.74[0.30]$ & & \\
\hline School/job functioning & $0.67[0.74]$ & & 0.44 \\
\hline Social activities & 0.56 & {$[0.56]$} & \\
\hline No symptoms to cope with challenges or crises & & $0.67[0.43]$ & \\
\hline Body experience & & $0.66[0.59]$ & \\
\hline Understand why one got an eating disorder & & $0.66[0.78]$ & \\
\hline Perfectionism & & $0.64[0.36]$ & \\
\hline Recognize feelings & & $0.63[0.82]$ & 0.38 \\
\hline Confident about feelings & 0.38 & $0.48[\mathbf{0 . 7 4}]$ & \\
\hline Weight & & & $0.75[0.78]$ \\
\hline Dieting and damaging symptoms & & & $0.74[0.67]$ \\
\hline General condition & & & $0.64[0.53]$ \\
\hline Quality of life & & $0.35[0.5 I]$ & 0.60 \\
\hline Menstruation & & & $0.55[0.72]$ \\
\hline Explained variation in \% & $21.30[19.1]$ & $15.90[16.9]$ & $15.70[15.0]$ \\
\hline Eigenvalues & $5.04[5.15]$ & $2.38[2.10]$ & $1.58[1.42]$ \\
\hline Internal consistency (Cronbach's alpha) & $0.84[0.83]$ & $0.72[0.83]$ & $0.73[0.7 I]$ \\
\hline Match with therapist group & $4 / 6(67 \%)$ & $3 / 5(60 \%)$ & $4 / 5(80 \%)$ \\
\hline
\end{tabular}

Notes: Factor loadings $\geq 0.50$ are printed in bold, and side loadings $<0.30$ are suppressed. Factor loadings and factor information for the general population sample $(\mathrm{N}=1052)$ are provided in brackets [ ] for reference. 
Table 6 A principal component analysis with varimax rotation

\begin{tabular}{|c|c|c|c|c|}
\hline \multirow{2}{*}{$\begin{array}{l}\text { Recovery items } \\
\text { Improvement of }\end{array}$} & \multicolumn{2}{|c|}{$\begin{array}{l}\text { Factors and factor loadings general } \\
\text { population and clinician sample }(\mathrm{N}=1204)\end{array}$} & \multicolumn{2}{|c|}{$\begin{array}{l}\text { Factors and factor loadings patient } \\
\text { validation sample }(N=184)\end{array}$} \\
\hline & Psychosocial aspects & Specific symptoms & Psychosocial aspects & Specific symptoms \\
\hline Family relations & 0.85 & & 0.87 & \\
\hline Relation towards mother & 0.83 & & 0.74 & \\
\hline Social network & 0.78 & & 0.68 & \\
\hline School/job functioning & 0.72 & & 0.55 & \\
\hline Weight & & 0.79 & & 0.70 \\
\hline Dieting and damaging symptoms & & 0.72 & & 0.68 \\
\hline Menstruation & & 0.71 & & 0.59 \\
\hline General condition & 0.39 & 0.63 & & 0.57 \\
\hline Explained variance in \% & 33.4 & 27.1 & 28.2 & 20.9 \\
\hline Eigenvalues & 3.34 & 1.50 & - & - \\
\hline Internal consistency (Cronbach's alpha) & 0.82 & 0.71 & 0.69 & 0.63 \\
\hline
\end{tabular}

Notes: Factor loadings $\geq 0.50$ are printed in bold. Side loadings $<0.30$ are suppressed. Eigenvalues $\geq 1$ were used as the extraction method for the general population and the clinician sample. A forced-entry two-factor extraction method was used for the patient validation sample. - indicates that there is no data.

the equation only three of 17 recovery items were sample specific. The fact that 14 items were sample unspecific in multivariate testing may serve as a strong confirmation of the expectation of sample commonality.

The second main finding is that the recovery items can be treated as a scale with adequate psychometric properties. A similar three-factor structure in the clinician and the general population sample may suggest that the condensed recovery scale has a fair convergent and external validity anchored in a general societal opinion. In addition, the fact that the final factor structure was replicated in the patient sample also suggests that the scale is clinically relevant. Hence, in multivariate analyses, both psychological and symptom-oriented recovery aspects "survived" both when considering the sample-specific factor analyses (Table 5) and the overall analysis (Table 6). The overall analysis may be a more critical test of multidimensionality. Again, however, items covered the relief of eating-disorder symptoms and weight normalization as signs of recovery, but also the patient's general condition, occupational functioning, and improvement in interpersonal relations. Hence, our findings indicate that clinicians, lay people, and eating-disorder patients do rely on a similar way of thinking about the multidimensional nature of recovery. Similar findings have been reported in the literature on the experiential approach to understanding recovery ${ }^{36,46}$ and on understanding recovery from other disorders. ${ }^{47}$

The strengths of this study are the use of samples large enough to allow for the multivariate testing of alternative measures, the random selection of a representative community sample, and the inclusion of a patient-validation sample.

Limiting the study was the response-set issue relating to format, where some items could have been reversed to control for acquiescence bias. ${ }^{48}$ With respect to content, the list of recovery items could have been longer and included more general positive aspects, for instance, the importance of happiness or a good income, to allow for a more thorough probing of a possible tendency to rate all positive things positively regardless of their relevance to eating disorders in particular. A longer list of eating-disorder-relevant issues might also have been a more appropriate test of the clinical validity of a final, condensed scale. Moreover, one can argue that our abbreviated final, eight-item scale (Table 6) overlooks some nuances relevant to recovery; but it is still multidimensional in nature and hence of value in outcome research where time limits and length of instruments can be critical factors.

Hence, patients, clinicians, and people from the general population converge around defining recovery in terms of improving family and social relations, improving occupational functioning, and improving disorder-specific symptoms. Future research should be directed toward validating the present factor structure and testing the sensitivity and specificity of "case identification" (ie, of identifying recovered patients) of the present scale against other psychometric devices ${ }^{23-26}$ that have been validated in clinical and general population studies ${ }^{49-53}$ and that are used in outcome evaluations.

A further search for congruence should include patients in various phases of recovery, to control for stage effects. On the other hand, this would require an independent set of multidimensional and psychometrically valid recovery criteria that are presently lacking, a requirement that motivated both this and previous research. ${ }^{34}$ Another future congruence test would need to include judging recovery from eating disorders both from the perspective of adolescent patients and 
from the perspectives of males and relatives. Also, despite crossovers between the eating-disorder diagnoses, ${ }^{42-44}$ future research should also explore differences in the judgments of recovery between diagnoses. This may be of interest in view of the outcome findings ${ }^{17,18}$ that a poor prognosis, and hence a failure to recover is related to physical symptoms and weight status for anorexia nervosa, to psychiatric comorbidity in bulimia nervosa and to interpersonal and psychosocial factors for binge eating disorders and unspecific eating disorders. Because we now have a relatively larger patient sample relative to the low base rate in the female population $^{54}$ and a five-times larger clinician sample, a new study is underway that addresses this issue even more properly than could be done in the current study. Finally, future studies of recovery judgments should adopt a longitudinal design, because such judgments may vary over time because recovery of physical and behavioral elements may occur before a recovery in terms of cognitive, emotional, and psychosocial elements. $^{6-8}$

\section{Disclosure}

The authors report no conflicts of interest in this work.

\section{References}

1. Agras WS. Nonpharmacological treatments of bulimia nervosa. J Clin Psychiatry. 1991;5:29-33.

2. Bardone-Cone A, Harney AM, Maldonado MB, et al. Defining recovery from an eating disorder. Beh Res Ther. 2010;48:194-202.

3. Cox G, Merkel W. A qualitative review of psychosocial treatments for bulimia. J Nerv Ment Dis. 1989;177:77-84.

4. Fairburn CG, Harrison PJ. Eating disorders. Lancet. 2003;361: 407-416.

5. Steinhausen HC. Outcome of eating disorders. Child Adolesc Psychiatr Clin NAm. 2009;18:225-242.

6. Clausen L. Time course of remission in eating disorders. Int $J$ Eat Disord. 2004;36:296-306.

7. Couturier J, Lock J. What is remission in adolescent anorexia nervosa? A review of various conceptualizations and quantitative analysis. Int J Eat Disord. 2006;39:175-183.

8. Couturier J, Lock J. What is recovery in adolescent anorexia nervosa? Int J Eat Disord. 2006;39:550-555.

9. Clinton DN, McKinlay WW. Attitudes to food, eating and weight in actually ill and recovered anorectics. Br J Clin Psychol. 1986;25: 61-67.

10. Fennig S, Fennig S, Roe D. Physical recovery in anorexia nervosa: is this the sole purpose of a child and adolescent medical-psychiatric unit? Gen Hosp Psychiatry. 2002;24:87-92.

11. Windauer U, Lennerts W, Talbot P, Touyz SW, Beumont PJ. How well are "cured" anorexia nervosa patients? An investigation of 16 weight-recovered anorexic patients. Br J Psychiatry. 1993;163: 195-200.

12. Fairburn CG. Cognitive Behaviour Therapy and Eating Disorders. New York, NY: The Guilford Press; 2008.

13. Darcy AM, Katz S, Fitzpatrick KK, Forsberg S, Utzinger L, Lock J. How former anorexia nervosa patients define recovery and engage in treatment. Eur Eat Disord Rev. 2010;18:260-270.

14. Björk T, Ahlström, G. The patient's perception of having recovered from an eating disorder. Health Care Wom Int. 2008;29:926-944.
15. Pettersen G, Thune-Larsen KB, Wynn R, Rosenvinge JH. Eating disorders: challenges in the later phases of the recovery process. Scand $J$ Caring Sci. June 7, 2012. DOI: 10.1111/j.1471-6712.2012.01006.x.

16. Rosenvinge JH, Pettersen G. Towards a comprehensive model of recovery. In: Jáuregui Lobera L, editor. Relevant Issues in Eating Disorders. Madrid, Spain: InTec Publishing House; 2012:169-192.

17. Berkman ND, Lohr KN, Bulik CN. Outcomes of eating disorders. Int J Eat Disord. 2007;40:293-309.

18. Keel PK, Brown TA. Update on course and outcome in eating disorders. Int J Eat Disord. 2010;43:195-204.

19. Williams SE, Watts TK, Wade TD. A review of the definitions of outcome used in the treatment of bulimia nervosa. Clin Psychol Rev. 2012;32:292-300

20. Björk T, Clinton D, Norring C. The impact of different outcome measures on estimates of remission in a 3-year follow-up of eating disorders. Eur Eat Disord Rev. 2011;19:2-11.

21. Arcelus J, Mitchell AJ, Wales J, Nielsen, S. Mortality rates in patients with anorexia nervosa and other eating disorders. Arch Gen Psychiatry. 2011;68:724-731.

22. Huas CG, Godart N, Caille A, et al. Mortality and its predictors in severe bulimia nervosa patients. Eur Eat Disord Rev. April 23, 2012. DOI: $10.1002 /$ erv. 2178 .

23. Bohn K, Doll HA, Cooper Z, O'Connor M, Palmer RL, Fairburn CG. The measurement of impairment due to eating disorder psychopathology. Beh Res Ther. 2008;46:1105-1110.

24. Fairburn CG, Cooper Z. The Eating Disorder Examination (12th version). In: Fairburn CG, Wilson GT, editors. Binge Eating: Nature, Assessment and Treatment. New York, NY: Guilford Press; 1993:317-360.

25. Garner DM. Eating Disorder Inventory-3. Professional Manual. Psychological Assessment Resources, Inc; Lūtz, Florida. 2004.

26. Garner DM, Olmsted MP, Polivy J. Development and validation of a multidimensional EDI for anorexia nervosa and bulimia. Int $J$ Eat Disord. 1983;2:15-34.

27. Fairchild H, Cooper M. A multidimensional measure of core beliefs relevant to eating disorders. Eat Beh. 2010;11:239-246.

28. Fairburn CG, Beglin S. Eating Disorder Examination Questionnaire (EDE-Q 6.0). In: Fairburn CG, editor. Cognitive Behavior Therapy and Eating Disorders. New York, NY: Guilford Press; 2008:209-313.

29. Morgan HG, Hayward AE. Clinical assessment of anorexia nervosa: the Morgan-Russell outcome assessment schedule. Br J Psychiatry. 1988; 152:367-371.

30. Lund C, Jörgensen, J, Bjerregaard K, Sørensen T. Interrater reliability of a Danish version of the Morgan-Russell scale for assessment of anorexia nervosa. Int J Eat Disord. 1999;25:105-108.

31. Freeman $\mathrm{K}$, et al. Low level of interrater reliability in a standard measure of outcome in eating disorders. Int J Eat Disord. 1996;20:51-56.

32. Vanderlinden J, Buis H, Pieters G, Probst M. Which elements in the treatment of eating disorders are necessary "ingredients" in the recovery process? A comparison between the patient's and therapist's view. Eur Eat Disord Rev. 2007;15:357-365.

33. Noordenbos G, Seubring A. Criteria for recovery from eating disorders according to patients and therapists. Eat Disord. 2006;14:41-54.

34. Emanuelli F, Waller G, Jones-Chesters M, Ostuzzi R. Recovery from disordered eating: sufferers' and clinicians' perspectives. Eur Eat Disord Rev. 2012. DOI: 10.1002/erv.2159.

35. Tozzi F, Sullivan PF, Fear JL, McKenzie J, Bulik CM. Causes and recovery in anorexia nervosa: the patient's perspective. Int J Eat Disord. 2003;33:143-154.

36. Pettersen G, Rosenvinge JH. Improvement and recovery from eating disorders: a patient perspective. Eat Disord. 2002;10:61-71.

37. Clinton DN, McKinlay WW. Attitudes to food, eating and weight in actually ill and recovered anorectics. Br J Clin Psychol. 1996;25: 61-67.

38. Vrabel KA, Rø Ø, Martinsen EW, Hoffart A, Rosenvinge JH. Five-year prospective study of personality disorders in adults with longstanding eating disorders. Int J Eat Disord. 2010;43:22-28. 
39. Butler NM, Slade P, Newton T. Attitudes towards anorexia nervosa and bulimic disorders: expert and lay opinions. Br Rev Bulimia Anorexia Nerv. 1990;4:61-69.

40. Schmidt U, Shirine A, Slone G, Tiller J, Treasure J. The Eating Disorders Awareness Test: a new instrument for the assessment of the effectiveness of psychoeducational approaches to the treatment of eating disorders. Eur Eat Disord Rev. 1995;3:103-110.

41. Hsu LKG, Crisp AH, Callender JS. Recovery in anorexia nervosa a patient perspective. Int J Eat Disord. 1992;11:341-350.

42. Castellini G, Lo Sauro C, Mannucci E, et al. Diagnostic crossover and outcome predictors in eating disorders according to DSM-IV and DSM-V proposed criteria: a 6-year follow-up study. Psychosom Med. 2011;73:270-279.

43. Tozzi F, Thornton LM, Klump KL, et al. Symptom fluctuations in eating disorders: correlates and diagnostic crossover. Am J Psychiatry. 2005;162:732-740.

44. Eddy KT, Dorer DJ, Franko DL, Tahilani K, Thompson-Brenner H, Herzog DB. Diagnostic crossover in anorexia nervosa and bulimia nervosa: implications for DSM-V. Am J Psychiatry. 2008;165: $245-250$

45. Rosenvinge JH, Perry JA, Bjørgum L, Bergersen TD, Silvera DH, Holte A. A new instrument measuring disturbed eating patterns in community populations: development and initial validation of a 5-item scale (EDS-5). Eur Eat Disord Rev. 2001;9:123-132.

46. Noordenbos G. Which criteria for recovery are relevant according to eating disorders patients and therapist? Eat Disord. 2011;19: $441-451$
47. Zimmermann M, Glinchey JB, Posternak MA, Friedman M, Attitullah N, Boerescu D. How should remission from depression be defined? Am J Psychiatry. 2006;163:148-150.

48. Knowles ES, Condon CA. Why people say "yes": a dual-process theory of acquiescence. J Pers Soc Psychol. 1999;77:379-386.

49. Root MP. Recovery and relapse in former bulimics. Psychotherapy: Theory Research Practice Training. 1990;27(3):397-403.

50. Clausen L, Rokkedal K, Rosenvinge JH. Validating the Eating Disorder Inventory (EDI-2) in two Danish samples: a comparison between female eating disorder patients and females from the general population. Eur Eat Disord Rev. 2009;17:462-467.

51. Clausen L, Friborg O, Rokkedal K, Rosenvinge JH. Validating the Eating Disorder Inventory-3 (EDI-3): a comparison between 561 female eating disorders patients and 878 females from the general population. $J$ Psychopathol Beh Assess. 2011;33:101-110.

52. Rø Ø, Reas D, Rosenvinge JH. The impact of age and BMI on Eating Disorder Examination Questionnaire (EDE-Q) scores in a community sample. Eat Beh. 2012;13:158-161.

53. Rø Ø, Bang L, Reas DL, Rosenvinge JH. The impact of age and BMI on impairment due to disordered eating in a large female community sample. Eat Beh. 2012 In press.

54. Hoek HW, van Hoeken D. Review of the prevalence and incidence of eating disorders. Int J Eat Disord. 2003;34:383-396.
Patient Related Outcome Measures

\section{Publish your work in this journal}

Patient Related Outcome Measures is an international, peer-reviewed, open access journal focusing on treatment outcomes specifically relevant to patients. All aspects of patient care are addressed within the journal and practitioners from all disciplines are invited to submit their work as well as healthcare researchers and patient support groups. Areas covered will

\section{Dovepress}

include: Quality of life scores; Patient satisfaction audits; Treatment outcomes that focus on the patient; Research into improving patient outcomes; Hypotheses of interventions to improve outcomes; Short communications that illustrate improved outcomes; Case reports or series that show an improved patient experience; Patient journey descriptions or research. 